\title{
El Edictum de Convicio
}

\author{
Al profesor Agerson T abosa, en ocasión de su homenaje, \\ con respeto y afecto.
}

\section{María José Bravo Bosch}

Professora titular de Direito Romano na Universidade de Vigo (Espanha)

bravobosch@uvigo.es

Resumen: Estudio sobre el edictum de convicio, un delito de injurias, caracterizado por ser una injuria verbal realizada de forma colectiva, con la intención clara de ofender a la víctima, independientemente de que esté presente o no ella misma en el momento de la ofensa. Era perseguido cuando se realizaba contra las buenas costumbres, concretadas como los mores huius civitatis. Se trata de un edicto especial al que se le ha prestado poca atención de forma individual, siendo nuestro propósito el identificar los elementos objetivos y subjetivos del mismo, a fin de que sea reconocido como figura singular.

Palabras clave: I niuria. E dictum. Convicio. B onos mores. D olus.

El delito de injurias es uno de los más antiguos y singulares del derecho romano, ya que como decía Del Prete ${ }^{1}$, la injuria, por su posición particular en el mundo ético, está más expuesta a sufrir la influencia de concepciones diversas, dependiendo de la evolución de los grados de una civilización. Iniuria², etimológicamente hablando,

1 DEL PRETE, La responsabilitá dello schiavo nel diritto penale romano, Roma, 1937, reimp. 1972, p. 34.

2 BERGER, Encyclopedic Dictionary of Roman Law, Filadelfia 1953, reimp. 1991, s.v. Iniuria; BRÉAL et BAILLY, Dictionnaire étymologique latin, París 19-, s.v. Iniuria; ERNOUT et MEILLET, Dictionnaire étymologique de la langue latine, París, 1959, s.v. Iniuria; FORCELLINI, Lexicon totius latinitatis 4, Patavii, reimp. 1940, s.v. Iniuria; HEUMANN - SECKEL, Handlexikon zu den Quellen des römischen Rechts, Jena, 1926, reimp. Graz. 1958, s.v. Iniuria; LEWIS\& SHORT, A Latin Dictionary, Oxford, 1966, reimp. 1995, s.v. Iniuria; WALDE, Latein. Etymologisches Wörterbuch, Heidelberg, 1965, s.v. Iniuria.

3 PLESCIA, "The development of iniuria", en Labeo 23, 1977, p. 271: "Etimologically iniuria is a compound word of in and ius the in being a negative particle and the ius meaning right and binding. Iniuria then would refer to whatever has been done non iure, i.e., contra ius, and it may be defined, in a very general sense, as a violation of another's rights either in deed or words". 
proviene del vocablo iure precedido del prefijo negativo in ${ }^{3}$, por lo que se infiere que todo acto non iure, contrario a derecho, se comprende dentro de la iniuria en un sentido amplio, como afirma Von Lübtow ${ }^{4}$ al hablar de "das Unrecht". En un sentido más técnico y estricto, se incluyen en esta denominación los más variados delitos, que causen daño o perjuicio aut re aut verbis -como señala Labeón en D. 47. 10. 1. 1- a la persona de otro o de sus dependientes. Aquí es donde debemos ubicar - por el tipo de ofensa realizada- la claúsula edictal de convicio, introducida por el pretor para sancionar los insultos o vocería proferidos por varias personas adversus bonos mores, reunidas en grupo o asamblea ante el domicilio de la persona a quien se injuria o en un lugar frecuentado por ella.

El presupuesto de hecho del ilícito pretorio se encuentra tipificado en la cláusula edictal, recogida por Ulpiano en D. 47, 10, 15, 2 (57 ad ed.), lo que demuestra la existencia del texto original del edicto de convicio: Ait praetor: Q ui adversus bonos mores ${ }^{5}$ convicium cui fecisse cuiusve opera factum esse dicetur, quo adversus bonos mores ${ }^{6}$ convicium fieret, in eum iudicium dabo.

${ }^{4}$ D Cfr. VON LÜBTOW, “Zum römischen Injurienrecht”, en Labeo 15, 1969, p. 163.

5 Paul. Coll. 2. 5. 2: "Commune omnibus iniuriis est, quod semper adversus bonos mores fit... "; vid. sobre la afirmación contenida en el texto de la Coll., RABER, Grundlagen klassischer Injurienansprüche, Viena-Colonia-Graz, 1969, p. 5 ss. en donde rechaza la afirmación de que toda iniuria, en cuanto sea jurídicamente relevante, sea realizada adversus bonos mores, ya que pueden darse casos de injuria en donde los boni mores no sean tomados explícitamente en consideración, añadiendo a continuación datos sobre la infracción de los boni mores; WITTMANN, "Die Entwicklungslinien der klassischen Injurienklage", en ZSS 91, 1974, p. 303-304. "Ein weiterer abstrakter Gesichtspunkt, den die Klassiker aus dem Edikt herleiten konnten, war das Kriterium des Handelns adversus bonos mores, das nur in drei Spezialedikten -im edictum de conviciis, im edictum de adtemptata pudicitia, und im edictum de iniuriis quae servis fiunt- explizit gennant war, von den Klassikern jedoch als im gesamten Bereich der actio iniuriarum ma geblich betrachtet wurde: Commune omnibus iniuriis est, quod semper adversus bonos mores fit idque non fieri alicuius interest (Paul. Coll. 2. 5. 2); MAYER-MALY, "Contra bonos mores", en Iuris Professio, Festgabe für Max Kaser, 1986, p. 157 ss.

${ }_{6}^{6}$ No entendido como un concepto abstracto, sino como se desprende de Ulpiano en D. 47. 10. 15. 6: Idem ait: <<adversus bonos mores $>>$ sic accipiendum, non eius, qui fecit, sed generaliter accipiendum adversus bonos mores huius civitatis. Vid. al respecto, MEZGER, Stipulationen und letztwillige Verfügungen "contra bonos mores" im klassisch - römischen und nachklassischen Recht, Göttingen, 1930, p. 18, cuando considera interpolado el fragmento desde non eius hasta accipiendum por ser ésta una explicación superflua; PÓLAY, Iniuria types, cit. p. 105, donde afirma que la expresión adversus bonos mores se refiere a "the boni mores in the state (this term meaning, therefore, objective measure)".

${ }^{7}$ Aparte del uso edictal, el vocablo convicium en ocasiones se utiliza para designar afrentas que pueden dar lugar a una represión pública, como señalan SANTA CRUZ/ D’ORS, “A propósito de los edictos especiales de iniuriis", en AHDE 49, Madrid, 1979, p. 657, en donde ponen como ejemplos: "cuando hay convicium, por parte de quien apela, contra el juez apelado (D. 49. 1. 8: non debere conviciari ei a quo appellat, y D. 47. 10. 42: iudici ab appellatoribus convicium fieri non oportet, cuya inserción en el título de la actio iniuriarum no implica que ésta fuera la acción apropiada); así también, cuando hay convicium contra el propio patrono, en cuyo caso impone un castigo el prefecto de la ciudad (D. 1. 12. 1. 10) o el gobernador provincial (D. 37. 14. 1). Estos convicia no tienen que ver con el edicto especial de convicio (§ 191)”. 
Si bien Maschke ${ }^{8}$ hablaba en un principio de una interpolación desde cuiusve hasta essey de quo a fieret, posteriormente cambió de parecer, entendiéndose el fragmento hoy en día libre de toda sospecha. Del texto se deduce la protección que concede el pretor ante hechos considerados muy graves en una sociedad romana que era extremadamente sensible en todo aquello que afectaba a la buena reputación y al honor $^{9}$, por lo que los insultos realizados en público, objeto de nuestro edicto ya que a decir de Watson: ${ }^{10}$ "Convicium means public insult", eran sancionados con severidad.

El motivo de la protección concedida por el pretor, en el último tercio del siglo II a.C. no es otro que el amparo del cives que sufre una afrenta verbal ${ }^{11}$, en público ${ }^{12}$, proferida por un grupo de personas que realiza la ofensa, por lo que la intervención dirigida a reprimir tal conducta nos demuestra que la actuación del magistrado era absolutamente

8 MASCHKE, Die Persönlichkeitsrechte des römischen Iniuriensystems, Breslau, 1903, p. 43.

9 Vid. al respecto, POMMERAY, Études sur l'infamie en Droit Romain, París, 1937, p. 113: "Le préteur, comme tout magistrat romain, attribuera à l'existimatio des individus une grande importance. Celle-ci sera tout particulièrement grande en raison de l'activité même qui est dévolue au préteur. C'est dans deux cas qui correspondent d'ailleurs à deux passages différents de son Edit, qu'il sera appelé à s'occuper de l'honorabilité des gens et à exercer son contrôle sur le libre jeu de l'infamie populaire.Tout d'abord, le magistrat s'est donné comme tâche de défendre le membre de la cité contr ceux qui voudraient faire naitre à son égard la réprobation populaire que nous avons décelée dans le type ancien; des moyens de droit seront accordés à celui qui se prétendrait ainsi incriminé à tort : à la rubrique de injuriis, tit. XXXV de l'Edit, les édits §191, 192 et 193, de convicio, de adtemptata pudicitia, et ne quid infamandi causa fiat »; sobre el significado de existimatio, GREENIDGE, Infamia. It's place in Roman Public and Private Law , reprint. Aalen, 1977, p. 1- 17.

${ }^{10}$ WATSON, The Law of Obligations in the later roman Republic, Oxford, 1965, reimp. 1984, p. 251.

${ }^{11}$ Cfr. CARNAZZA-RAMETA, Studio sul Diritto penale dei romani, ed. anast. Roma, 1972, p. 214, en donde dice que la injuria se podía cometer verbis, y que el edicto del pretor se ocupó de las injurias verbales que eran privadas o públicas, división mantenida en los códigos modernos; la injuria privada era un maledictum, no tenía la importancia de la segunda que para constituirla era necesario el convicium por concitatio o conventus o collatio vocum; MÉHÉSZ, La injuria en Derecho Penal Romano, Buenos Aires, 1969, p. 30, en donde define el convicium como una injuria inmediata verbal, a lo que añade que la injuria verbal era muy común en Roma: "porque ahí nunca faltaban los impertinentes y groseros, que con vocerío vulgar y palabras torpes, sabían como amargar a sus víctimas".

${ }^{12}$ Precisamente contra la difamación efectuada sin la presencia de público, no existía protección alguna, hasta la emanación del edicto ne quid infamandi causa fiat (posterior al de convicio), que comprende cualquier ilícito que se realice infamandi causa fiat. En palabras de DAUBE, Ne quid infamandi causa fiat, en Collected Studies in Roman Law I, Frankfurt, 1991, p. 469, la aparición de este edicto "Was a tremendous innovation, the effects of which are still felt in our day. Any human act might come under the prohibition; and wether or not a given act did come under it was to depend, in the first place, on the intent with which it was done. It was the craftiness of those out to destroy the good name of others which had led to this triumph of a 'subjective' criterion. As they had demonstrated that there was practically no act which could not be used for the purpose of defamation, the only thing for the praetor to do was to include any act having that purpose". 
necesaria por la multitud de casos acaecidos en la sociedad romana de la época ${ }^{13}$. Ayuda a comprender la importancia de este edicto el hecho de que el pretor lo promulgase como primer edicto especial después del edictum generale de iniuriis aestimandis, para proporcionar fundamento legal a las ofensas cometidas contra el honor.

La palabra convicium ha suscitado desde hace tiempo las dudas de los intérpretes y los críticos. Tiene razón Huvelin ${ }^{14}$ cuando afirma que convicium facere, en su sentido técnico, no se aplica más que al hecho de una persona que, junto con otras, o al menos en medio de otras, vocifera, entendiendo como tardía la posibilidad de que convicium tenga el significado de insulto realizado por una sola persona, tema debatido constantemente por la doctrina, en cuanto a si el convicium se podía realizar sólo por parte de un grupo de personas o incluso por alguien de forma singular. Esta posibilidad de la afrenta singular es mantenida por Raber ${ }^{15}$, en el sentido de aceptar como convicium el realizado por una sola persona, ya que de acuerdo con D. 47, 10, 15, 12, los requisitos cum vociferatione e in coetu se pueden entender como referidos no necesariamente a una pluralidad de sujetos, ya que se dice sive unus al principio del texto.

Algunos, como Fraenkel ${ }^{16}$, afirman la relación entre la noción edictal privada de convicium y la decenviral del carmen famosum (recitado o cantado: occentare; escrito: carmen condere), documentada en un pasaje de Festo, afirmando que el occentare en las XII Tablas ya gravitaba en la esfera de la difamación verbal. Otros, como Manfredini ${ }^{17}$, recurren a la etimología del vocablo para hablar de su naturaleza colectiva: cum e voces, pero incidiendo en que la noción originaria de convicium nada tiene que ver con la difamación a través de las palabras ni con la difamación escrita contenida en un carmen, liber o libellus, sino que se refería a gritos y alborotos colectivos, dirigidos como protesta sobre todo contra primores.

Es cierto que el comentario de Ulpiano sobre la cláusula de progenie edictal recogida en D. 47, 10, 15, 2, nada dice acerca del significado de convicium. Pero hay otro pasaje del propio Ulpiano, reproducido en D. 47, 10, 15, 4, (57 ad. ed.) que nos brinda el significado

\footnotetext{
${ }^{13}$ Las fuentes literarias describen a la sociedad romana de los últimos tiempos de la República y de los primeros siglos del Imperio como una civitas calumniadora, que ridiculizaba, criticaba y sometía a escarnio público a todo el mundo, sin respeto por nadie, y siempre dispuestos a la mofa y burla de cualquiera, ya sea adversario, conocido o amigo, como se aprecia en Cic. Pro Cael. 38, Quaest. Tusc, 4. 2; Hor. Sat. 1. 4. 75; id. 86-89; Ibid. 1. 7. 20 ss.; Juv. Sat. 102-120, Suet. Caes. 22, 49.

${ }^{14}$ HUVELIN, La notion de l'iniuria dans le très ancien droit romain, Lyon, 1903, reimp. Roma, 1971, p. 59.

${ }^{15}$ RABER, Grundlagen, cit., p. 27 ss.

${ }^{16}$ FRAENKEL, "Rec. a Beckmann. Zauberei und Recht im Romsfrühzeit", en Gnomon 1, 1925, p. 193-194.

${ }^{17}$ MANFREDINI, La diffamazione verbale nel Diritto Romano, Milán, 1979, p. 61.
} 
etimológico de convicium: Convicium ${ }^{18}$ autem dicitur vel a concitation $e^{19}$ vel a conventu ${ }^{20}$, hoc est a coll atione vocum; cum enim in unum complures voces conferuntur ${ }^{21}$, convicium appellatur, quasi convocium.

El interés suscitado en la doctrina por lo que se refiere a este pasaje se infiere de la necesidad de circunscribir el ámbito del edicto de convicio. Así, mientras unos, como Hendrickson ${ }^{22}$, apuestan por la posibilidad de que constituya conducta punible

${ }^{18}$ Imprescindible la lectura de Th. 1. 1. s. v. convicium: orig. inc. sunt qui conferant c. vocare, vox, en donde cita a Festo, De verb. cit. s. v. convicium, y a Ulpiano en este texto del Digesto, así como a Non. p. 64: convicium dictum est quasi e vieis logi, in quis secundum ignobilitatem loci maledictis et dictis turpibus cavilletur; Boeth. top. Arist. 6, 3, p. 976d: qui convicium iniuriam cum irrisione definivit; Ov. met. 6, 362. 13, 306. 14, 522. Como otro significado, i. q. exprobatio cum clamore facta, maledictum probrium, acris vituperatio, sim. Por lo que se refiere a las fuentes literarias en cuanto a su significado generatim: Plaut. Bacch. 874, Cic. Verr. 2, 158: hominum clamore atque convicio; 5, 141.6, 28:erant convivia... cum maximo clamore atque convicio. Or. Frg. A 6, 1: fit clamor, fit convicium mulierum. El Th. 1. l. nos proporciona además los posibles synonima: clamor, contumelia, detestatio, improperium, infamia, iniuria, insectatio, lis, maledictum, obiurgatio, opprobium, pipulum, probrum, rixa, sibilus, strepitus, vellicatio, vociferatio.

${ }^{19}$ Th. 1. l. s. v. concitatio; significado en sentido propio: vehemens motus, excitatio, agitatio; en sentido translaticio: motus, incitatio populi, militum, multitudinis. Incluso parece obligada la referencia que hace a s.v. concitare, II B: de sedictione ac tumultu; cfr. Quint. xi. 3. 175: fortis et vehemens et latro erecta et concitata voce dicendum est; Val. Max. ix 3.8 : animi concitatione nimia atque immoderato vocis impetu.

${ }^{20}$ Cfr. Th. l. l. s. v. conventus: signif. I A: concursus, congregatio; Paul. Diac. s.v. conventus (L. 36) : Conventus quattuor modis intellegitur. Uno, cum quemlibet hominem ab aliquo conventum esse dicimus. Altero, cum significatur multitudo ex conpluribus generibus hominum contracta in unum locum. Tertio, cum a magistratibus iudicii causa populus congregatur. Quarto cum aliquem in locum frequentia hominum supplicationis aut gratulationis causa conligitur, siendo el núcleo central del significado la pluralidad de personas citadas en un lugar.

${ }^{21}$ Vid. al respecto, PÓLAY, Iniuria types, cit. p. 103, en donde habla del convicium "Commited by more persons than one, who shout together (conferuntur)", añadiendo en p. $146 \mathrm{n} .21$ que la expresión de D. 47, 10, 15, 12 sive unus, sive plures dixerint está en contradición con el supuesto original (con-vocium) ya que el grito de una sola persona no puede realizar esta clase de iniuria. Para él, resulta evidente que puede tratarse de una interpretación postclásica extensiva del significado original.

${ }^{22}$ HENDRICKSON, "Convicium", en Cl. Ph. 21, n 2, 1926, p. 116 ss. en donde hace un análisis exhaustivo del texto de Ulpiano, del que destaca que en un lenguaje que semeja llano e inequívoco, aparentemente los juristas modernos se dieron cuenta del hecho de que son dos las interpretaciones posibles ofrecidas, exactamente como las de los antiguos gramáticos en las presentes etimologías, por ejemplo, Paulus ex Festo s. v. convicium : "a vicis...videtur, dictum, vel inmutata littera quasi convocium". La primera definición, a concitatione, da la idea de concentración o intensidad "that is of noise, or, as is said presently, vociferatio"; la segunda, a conventu, "of a plurality of speakers". Así, Ulpiano tendría en mente dos posibles acepciones del convicium, una desde el punto de vista de la vociferatio, otra dependiendo del número de los que vociferan, coetus. Continua el autor diciendo: "In sections 11 and 12 there is an apparent blending of these points of view, which has I suspect been the source of the error noted in the citations from the modern jurists at the beginning of this paper", todo ello por la pérdida de la partícula vel que para Hendrickson debía estar en el texto: ex his apparet non omne maledictum convicium esse, sed id solum quod cum vociferatione dictum est,... [b] < vel> quod in coetu dictum est, convicium est. "That this sharp twofold division - obscured by the loss of vel- is intended, appears from the words following: 
el convicium proferido por una sola persona, otros como Wittmann ${ }^{23}$ - que representa la opinión de la mayoría- niegan por el contrario el ilícito realizado de forma individual, afirmando que el edicto condena única y exclusivamente la actitud de una pluralidad de personas. Para él, Ulpiano se limitó a ofrecer en el pasaje un cuadro etimológico del término convicium, con dos posibles acepciones, siendo la primera: vel a concitatione, vel a conventu, y la segunda, por la que Ulpiano se decanta: cum enim in unum conplures voces conferuntur, convicium appellatur quasi convocium.

Ambas teorías relacionan la etimología de convicium prevista en D. 47, 10, 15, 4, con el contenido de lo dispuesto en D. 47, 10, 15, 11- 12, cuyo tenor literal es el siguiente:

Ex his apparet, non omne maledictum ${ }^{24}$ convicium esse: sed id solum, quod cum vociferatione dictum est. Sive unus, sive plures dixerint, quod in coetu dictum est, convicium est: quod autem non in coetu, nec vociferatione dicitur, convicium non proprie dicitur, sed infamandi causa dictum.

quod autem [b]non in coetu [a]nec vociferatione dicitur, convicium non proprie dicitur, sed infamandi causa dictum", para terminar diciendo que la creencia de que convicium implica la presencia de una multitud o muchedumbre es claramente errónea. Merece la pena traer a colación las conclusiones del filólogo, cuando afirma en la p. 119: "It is spun out of an assumed etymology, which Ulpian does not in fact entirely indorse, but merely advances in explanation of one aspect of his twofold conception of convicium. But while not accepting it unreservedly, he yet rests one leg of his structure upon it. This is the starting point of the modern doctrine, which, failing to note the alternatives, has accepted the idea of a plurality of voices or persons as the unqualified teaching of the jurists. Convicium has necessarily no more to do with a plurality of utterance than has clamor, or the ancient pipulum and vagulatio, both of which are defined by convicium. To be sure a mob might shout insults at an individual, and these were convicia, not however, because they were shouted by a crowd or in chorus -quasi convocium, but because they were vehement expressions of hostile feeling- a concitatione, and meant to overwhelm (convincere)"; ya anteriormente, CARNAZZA-RAMETA, Studio sul diritto, cit. p. 214, cuando define el convicium como la propagación de la iniuria realizada por una o más personas en un lugar público, como en una plaza, en una posada o en un camino; del mismo modo, JÖRS-KUNKEL-WENGER, Römisches Privatrecht, Berlín-Gotinga-Heidelberg, 19493, p. 259, traducían la palabra convicium con la expresión "gemeinsames Schreien mehrerer Personen", que podía cometer alguien incluso solo; como seguidor de esta teoría, vid. RABER, Grundlagen, cit. p. 27 ss, en donde argumenta que también una sola persona puede hacer convicium.

${ }^{23}$ WITTMANN, "Die Entwicklungslinien der klassischen Injurienklage", en ZSS 91, 1974, p. 308; anteriormente, en Die Körperverletzung an Freien im klassischen römischen Recht, Munich, 1972, p. 29, se refería ya al convicium de la siguiente forma: "convicium ist jedenfalls ursprünglich ein Schimpfkonzert, das von mehreren gegen jemanden veranstaltet wird”, quedando claro el espíritu colectivo de los que realizan una afrenta verbal contra otro.

${ }^{24}$ Vid. al respecto, FERRINI, Diritto Penale Romano. Teorie generali, Milán, 1899, p. 236, en donde dice que si el maledictum no es público, no puede considerarse "infamatio"; ZIMMERMANN, The Law of Obligations. Roman Foundations of the Civilian Tradition, Oxford, 1996, p. 1054, cuando afirma que no todo tipo de ofensa verbal era convicium, ya que "It had to be bawled aloud (id solum, quod cum vociferatione dictum est), and it had to be voiced within a crowd of people (...quod in coetu dictum est), sin pronunciarse sobre la posibilidad de que una sola persona pueda cometer convicium, apuntando tan sólo en forma interrrogativa si tal opción podía acontecer: "Could an individual person commit the offence of convicium?". 
Del contenido del texto se infiere la no consideración de convicium ante cualquier afrenta verbal ${ }^{25}$, siendo imprescindible el requisito de elevar la voz, cum vociferatione, y con intención de lesionar el honor de otra persona. También es necesaria la presencia de un grupo de personas ante las que se realiza la vocería ${ }^{26}$, puesto que si no existe una multitud de personas cuando se profiere el ilícito contenido en el convicium, no se gozaría de la protección de pretor. Por lo que resulta clara la necesidad de que ambos supuestos se den a la vez, es decir: si existe vociferación, pero no en presencia de un grupo de gente, no existirá convicium, y al revés. Esta obligación cumulativa de ambos supuestos se produce porque en ausencia de alguno de estos requisitos, estaríamos ante el infamandi causa dictum no ante un caso propio de convicium ${ }^{27}$.

Por lo que hace al fr. 12, debemos poner de manifiesto que seguramente sea un requisito de época clásica la participación de varios sujetos profiriendo insultos a otro, mientras que la posibilidad prevista sive unus, de incurrir en el ilícito edictal cuando es una sola persona la que realiza la vocería puede ser de progenie postclásica, aunque la doctrina resulta difusa en torno a este punto, siempre sometido a meras hipótesis. Con todo, no es menos cierto que en medio de una turba encolerizada que insulta a alguien $^{28}$, resulta dudoso pensar que tan sólo sea uno el que participe de forma directa

${ }^{25}$ Cfr. PUGLIESE, Studi sull' "iniuria", Milán, 1941, p. 53, en donde declara: "Inoltre occorre tenere presente che il convicium non è propriamente un'ingiuria verbale, ma qualcosa di più caratteristico, come è ripetuto ancora da Ulpiano (D. 47, 10, 15, 11), ed è pure una figura tipicamente romana, in quanto non ha riscontro, a quel che pare, in nessun delitto greco".

${ }^{26}$ Cfr. SANTACRUZ/D’ORS, "A propósito de los edictos", cit. p. 657: "El concurso de varias personas es esencial para este tipo delictual, aunque no es necesario que las voces ofensivas sean proferidas por todas o muchas de ellas, sino que basta que lo sean por una; pero, si no hay concurso, las palabras injuriosas proferidas por alguien quedan sancionadas por el otro edicto especial contra actos difamatorios, como aclara Ulpiano", optando por la posibilidad de que exista convicium aunque sea tan sólo uno el que profiera la ofensa verbal.

${ }^{27}$ Cfr. WITTMANN, "Die Entwicklungslinien", cit. p. 310, en donde dice que Ulpiano impone para la noción de convicium dos condiciones que tienen que existir a la vez: "Die kumulativ vorliegen müssen. Die Beschimpfung mu mit lauter Stimme (cum vociferatione) und öffentlich (in coetu) erfolgen”. Para Witmann, la locución sed id solum, quod cum vociferatione dictum est, sive unus sive plures dixerint, quod in coetu dictum est, convicium est, se debe entender en el sentido de que para Ulpiano no podía darse el convicium sin vociferatio, y aunque D. 47, 10, 15, 12, hable de quod autem non in coetu nec vociferatione dicitur, en vez de quod autem non in coetu aut non vociferatione dicitur, ello no significa que bastase para la existencia del convicium solamente el in coetu dictum o la vociferatio, siendo necesaria la concurrencia de ambos requisitos cumulativamente. Es decir, para que se pueda dar el supuesto punible, debe existir -además de una multitud- el autor o autores del convicium, que deben proferir el insulto con vociferación influyendo en los que conforman la muchedumbre, y no en voz baja de modo que nadie comprenda lo que dicen.

${ }^{28}$ Vid. al respecto, AJA SÁNCHEZ, "Plebs contra Dominum (in Edessa). La modalidad del «convicium» como forma de expresión de la «iustitia populi», en Homenaje al profesor Montenegro Duque,Valladolid, 1999, p. 728, cuando al referir la vejación de la estatua de Constancio II en Edessa, suceso conocido a través del testimonio de Libanio, en Orat. XIX. 48 y XX. 27 y acaecido en el siglo IV, dice lo siguiente: “....Libanio tampoco fue 
en la afrenta verbal y pública contra otro. Por todo ello, resulta más acorde con la lógica pensar que el pretor quiso condenar la conducta ilícita de un grupo de individuos que realizan convicium a otro, es decir, que insultan como conjunto a una persona, y que buscan como resultado el menoscabo del honor de la misma.

A mayor abundamiento, en D. (h. t.) fr. 8, encontramos la siguiente consideración del jurista Ulpiano:F ecisse convicium non tantum is videtur, qui vociferatus est, verum is quoque, qui concitavit ad vociferationem alios vel qui summissit ut vociferentur.

Suponemos, a la vista de este fragmento, que se podía dar en ocasiones que hubiese un instigador, que sublevase a una muchedumbre para que profiriese el convicium, aun cuando él mismo no estuviese presente en la realización del acto ilícito, ya que nada dice Ulpiano de la necesidad de que esté presente el que concita a otros a vociferar o los envía para que vociferen. Por lo tanto, se presupone la existencia de diversos sujetos activos en la realización del convicium, siendo punible la conducta de todos los que hayan intervenido en la ofensa, aún cuando directamente no hayan proferido el convicium condenable. Esto vendría en ayuda de la tesis de Wittmann, según la cual sólo es posible el convicium realizado por varios, aun cuando persiste la duda de qué hacer ante un caso de convicium proferido por uno solo, y sin la instigación de nadie, sin olvidar que el vocablo convicium nos refiere la necesidad de un conjunto de voces ${ }^{29}$.

Acabamos de ver como para subsumir una determinada conducta en el concepto de convicium resultan necesarios ciertos requisitos (vociferación, conjunto de voces, tumulto, insultos). Del mismo modo, para que una afrenta verbal sea considerada objeto de reprobación debe efectuarse contra bonos mores, debiendo analizar a continuación que significado se le debe atribuir a los boni mores, pudiendo así saber cuando se contravienen esas buenas costumbres, y se actúa adversus bonos mores.

especialmente explícito al referirse a los autores del derribo y vapuleo humillante sufrido por la estatua. Tan solo señaló a "los habitantes de la ciudad", en un sentido así de amplio y general, como los responsables y autores materiales de la ofensa al emperador, ello cuando no prefiere referirse a «la ciudad», como si toda la población hubiera participado de una u otra forma en el suceso, ya que es siempre de este modo genérico como alude a los culpables y autores materiales de la afrenta al eikon imperial"; además, en p. 732, al hablar de la existencia de un "convicium in effigiem", ante el que el emperador adopta una actitud de silencio y de perdón, comenta que este acto popular de desacato frente al poder central proviene de una antigua y popular tradición edessense, por lo que Libanio consideró justificable la conducta de los habitantes de la ciudad cuando hicieron convicium a la estatua del emperador, pero solo porque ello formaba parte de una costumbre de larga tradición; cfr. sobre la mención más detallada del suceso, GLEASON, "Festive satire: Julian's Misopogon and the New Year at Antioch", en JRS 76, 1986, p. 106-119, en donde además refiere el tumulto popular más conocido del siglo IV, el ocurrido en Antioquía en el año 387 (posterior al de Edessa), cuando la población injurió una serie de estatuas de la familia imperial, con gran repercusión en el mundo antiguo.

${ }^{29}$ MARRONE, "Considerazioni in tema di iniuria", en Synteleia Arangio-Ruiz, Nápoles, 1964, p. 479, cuando declara: "Convicium vuol dire riunione di più voci: consisteva nello schiamazzo ingiurioso, effettuato da un grupo numeroso di persone presso l'abitazione di alcuno, durante il quale, tra l'altro, si proclamavano ad alta voce torti e colpe della vittima". 
La referencia a las buenas costumbres entre los juristas es muy frecuente ${ }^{30}$, hablando incluso del papel decisivo que la contravención de las mismas, como norma objetiva, tiene en los diferentes tipos de iniuria ${ }^{31}$. Ahora bien, como dice Mezger ${ }^{32}$, la percepción de la máxima contra bonos mores referida a la moral, que es el significado que se le suele atribuir, no es propio del Derecho clásico, sino de la etapa postclásica, siendo nuestra labor la de concretar la acepción de los bonos mores previstos en el edicto del pretor, como recoge Ulpiano en el texto ya citado D. 47. h. t. 2: Q ui adversus bonos mores convicium cui fecisse.. quo adversus bonos mores convicium firet, in eum iudicium dabo.

A tenor de lo dispuesto por el magistrado, resulta indispensable la combinación de convicium con adversus bonos mores, por cuanto la conducta punible la constituye la injuria verbal cometida contra las buenas costumbres ${ }^{33}$, y sólo en ese caso será condenado el insulto. A mayor abundamiento, Ulpiano concreta en D. 47. 10. 15. $5^{34}$ la declaración

${ }^{30}$ KASER, Das Römische Privatrecht I3, Munich, 1971-1975, p. 195-196; traemos a colación las palabras de Paulo contenidas en D. 47, 11, 1, 1: Fit iniuria contra bonos mores, veluti si quis fimo corrupto aliquem perfuderit, coeno, luto oblinierit, aquas spurcaverit, fistulas, lacus, quidve aliud ad iniuriam publicam contaminaverit; in quos graviter animadverti solet.

${ }^{31}$ Como se puede comprobar en el testimonio de Paulo recogido en D. 47, 10, 33 (10 ad Sab.): Quod reipublicae venerandae causa secundum bonos mores fit, etiam si ad contumeliam alicuius pertinet, quia tamen non ea mente magistratus facit, ut iniuriam faciat, sed ad vindictam maiestatis publice respiciat, actione iniuriarum non tenetur, lo que se hace según bonos mores para venerar a la república -aunque sea en afrenta de alguien- no está sujeto a la acción de injurias; incluso en el edicto suplementario de iniuriis quae servis fiunt, recogido en D. 47, 10, 15, 34: Praetor ait: qui servum alienum adversus bonos mores verberavisse, deve eo iniussu domini quaestionem habuisse dicetur, in eum iudicium dabo; item si quid aliud factum esse dicetur, causa cognita iudicium dabo; asimismo, en D. h. t. 38: Adiicitur: «adversus bonos mores», ut non omnis omnino, qui verberavit, sed qui adversus bonos mores verberavit, teneatur; ceterum si quis corrigendo animo, aut si quis emendandi, non tenetur".

${ }^{32}$ MEZGER, Stipulationen, cit. p. 4: "Nach allgemeiner Anschauung soll contra bonos mores den Versto gegen das Sittlichkeits oder Moral gesetz bezeichnet haben. Ich glaube nicht, da dies der Standpunkt des klassischen Rechtes war", sino de la época postclásica, apuntando el hecho de que el cristianismo fue el que introdujo una consideración más fuerte de la moral.

${ }^{33}$ Vid. al respecto, MARRONE, "Considerazioni", cit. p. 480, en donde dice que el convicium era un concepto bastante difuso por lo que mereció la atención del pretor, el cual concedió una pena pecuniaria privada contra los autores de un convicium adversus bonos mores, precisando que no se trataba de mores individuales, sino de los mores de la civitas, como se desprende de D. 47. 10. 15, 6, que luego analizaremos en profundidad. Añade que el convicium continuó siendo lícito, con tal de que esté justificado, a condición de que se realice en la confrontación con un indigno, "di un individuo che avesse in sostanza meritato quella condanna popolare, di cui il convicium era al contempo la pronunzia e l'esecuzione".

${ }^{34}$ Sobre la interpretación de este texto, WITTMANN, "Die Entwicklungslinien", cit. p. 313-314, en donde señala que la comprensión clásica del criterio edictal de la acción adversus bonos mores es tratada por Ulpiano en D. 47. 10. 15. 5, en donde se recogen los posibles comportamientos de los autores que infrinjan los boni mores; MANFREDINI, la diffamazione verbale, cit. p. 72 n. 108, en donde dice que en el tratamiento ulpianeo de la noción edictal de convicium, "proprio perchè il giurista non si pone in una netta prospettiva storica consapevolmente scelta ma ad essa approda indirettamente, attraverso il commento lemmatico dedicato alla clausola edittale dai precedenti commentatori ad edictum che egli mette a profitto", se asiste a una interferencia entre reglas y conceptos del pasado con las actuales, en vigor en la época del jurista. 
realizada por el pretor: Sed quod adiicitur a Praetore: «adversus bonos mores», ostendit, non omnem in unum collatam vociferationem Praetorem notare, sed eam, quae bonis moribus improbatur, quaeque ad infamiam vel invidiam alicuius spectaret.

La parte quaque ad infamiam, vel invidiam alicuius spectaret, es entendida por algunos como una interpolación, posiblemente realizada, ya que el sentido originario de la cláusula edictal se ve perturbado por la inserción de esta última frase ${ }^{35}$. Por lo tanto, sólo la vociferación reprobada por las buenas costumbres es susceptible de ser perseguida, y no cualquier otra manifestación ruidosa de voces. Y en el párrafo siguiente, D. 47 h. t. 6, el jurista Ulpiano nos refiere la realidad del alcance de la expresión "adversus bonos mores" 36. I dem ait: "adversus bonos mores » sic accipiendum, non eius, qui fecit, sed generaliter accipiendum adversus bonos mores huius civitatis.

La concreción ahora resulta meridianamente clara. Lo que importa no es si el autor contravino su propia concepción de las buenas costumbres, es decir, aquí el concepto de bonos mores no se refiere a las buenas costumbres del autor del ilícito, sino que deben ser asumidas en un ámbito concreto: contra las buenas costumbres de la ciudad. Dicho esto, debemos dejar constancia de la teoría de Mezger ${ }^{37}$, que habla de una interpolación desde non eius hasta generaliter accipiendum, lo que facilitaría todavía más la comprensión del texto. Así, lo que se dirime no son los bonos mores del autor de la injuria verbal - algo superfluo- sino la interpretación de los bonos mores en el sentido de los huius civitatis, como medida objetiva. A tenor de lo dispuesto, resulta mucho más sencilla la tarea de identificar cuando se contravienen las buenas costumbres -en el sentido de los bonos mores de la civitas- siendo un ámbito concreto el que delimita la acción ilícita. No cabe duda de que en caso contrario, si se hiciese depender la condena de la conducta adversus bonos mores de un ámbito más amplio, o de un concepto vagamente delimitado (contra las buenas costumbres de los romanos -por ejemplo- sin especificar más) hubiese sido tarea harto díficil el condenar a los que hubiesen proferido una afrenta verbal a otra persona.

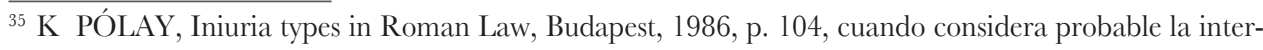
polación "because the text -if not interpolated in this part- would already mean the connection of the edict-clauses arranging the concepts of convocium and infamandi causa".

${ }^{36}$ Cfr. RABER, Grundlagen, cit. p. 24 ss. en donde sostiene que el atentado contra las buenas costumbres es un elemento objetivo; contra, WITMANN, "Die Entwicklungslinien", p. 314, para quien el hecho de que sean los mores de la civitas el referente para determinar la conducta ilícita, "folg nicht die Objektivierung des Kriteriums des Handelns adversus bonos mores in dem Sinne, dadie Rufschädigungsabsicht, sobald objektiv die Mibilligung des Verhaltens des Täters durch die boni mores feststeht, unbeachtlich wäre. Diese muvielmehr zur objektiven Nichtübereinstimmung des Verhaltens mit den boni mores hinzukommen".

${ }^{37}$ MEZGER, Stipulationen, cit. p. 18.
} 
Por lo que se refiere a los que sufren la realización del convicium, que resultan afectados por la vocería de un grupo que profiere insultos y descalificaciones contra su persona, debemos interesarnos por las palabras pronunciadas por Labeón, recogidas por Ulpiano en D. 47, 10, 15, 7, en donde se determina lo siguiente:

Convicium non tantum praesenti, verum absenti quoque fieri posse, Labeo scribit. Proinde si quis ad domum tuam venerit te absente, convicium factum esse dicitur. I dem et si ad stationem vel tabernam ventum sit, probari oportere.

El texto precisa quién puede ser afrentado con el convicium, aclarando que no se exige la presencia del sujeto -una persona $\operatorname{concreta}^{38}$ - para que se produzca el ilícito, sin duda porque lo que protege el edicto es el honor de la persona que se ve insultada por otros, por lo que resulta indiferente que el individuo esté o no en su domicilio, incluyendo un punto de parada o una hostería. Lo que se condena aquí es la vulneración de los derechos del otro, la difamación realizada directamente contra una persona $^{39}$, en presencia de un grupo que participa de la afrenta ${ }^{40}$, motivo por el cual el Pretor concederá una acción, la actio iniuriarum.

Es obvio que para que exista el convicium se debe realizar la injuria a una persona cierta, concreta, determinada, no siendo posible la protección prevista en el edicto del Pretor si la vocería no se puede identificar como lesiva a los intereses de un sujeto determinado. Es decir, si alguien profiere insultos en grupo, pero no se sabe contra

\footnotetext{
${ }^{38}$ HAGEMANN, Iniuria, Von den XII Tafeln bis zur Justinianischen Kodifikation, Colonia, 1998, p. 70: "Ein convicium kann auch gegen eine bestimmte abwesende Person verübt werden"; vid. en relación con el concepto de persona determinada, la acción de injurias concedida en caso de error con respecto a la identidad de alguien, prevista en D. 47. 10. 18. 3 (Paul. 55 ad ed.): Si iniuria mihi fiat ab eo, cui sim ignotus, aut si quis putet, me Lucium Titium esse, quum sim Caius Seius, praevalet quod principale est, iniuriam eum mihi facere velle; nam certus ego sum, licet ille putet me alium esse, quam sum, et ideo iniuriarum habeo.

${ }^{39} \mathrm{Cfr}$. PÓLAY, Iniuria types, cit. p. 145-146, cuando dice que la parte injuriada no necesita estar presente cuando se comete convicium, ya que se puede realizar contra una persona ausente, siendo sólo esencial que se profiera el ilícito directamente "against his (her) person and be contra bonos mores ".

${ }^{40}$ MARRONE, "Considerazioni”, cit. p. 485, cuando declara que lo que se reprime es la afrenta misma, directa o indirecta, a la fama o consideración de una persona, que le puede suponer a esa víctima una disminución o anulación de su capacidad jurídica (lo que ponemos en relación con el elemento subjetivo del ilícito, que veremos posteriormente). Añade que bastaba que la acción del ofensor se realizase en un sitio público para que su conducta pudiese ser condenada, "sulla pubblica via, nel Foro... in modo che molti vedessero e sentissero. Le fattispecie dell fonti sono tutte di questo tipo e non occorre citarle una per una per sottolineare in esse la presenza del particolare requisito della publicità", limitándose a recordar como eso resulta evidente en el primer edicto especial pretorio en materia: el edicto de convicio.
} 
quién van dirigidos, al no haber sujeto pasivo no existirá la tutela del edicto de convicio. Con patente rotundidad nos refiere Ulpiano en D. 47, 10, 15, 9 la siguiente afirmación: «C ui» non sine causa adiectum est; nam si incertae personae convicium fát, nulla executio est.

Se condena la realización del acto que produce daño en la víctima, daño real y lesivo para su honor, sin reconocer como conducta imputable la actitud del que desea que profieran convicium a alguien, sin conseguirlo, por el motivo que sea, como se desprende de Ulpiano en D. (h. t.) fr. 10: Si curaverit quis convicium alicui fieri, non tamen factum sit, non tenebitur. Lo importante es el resultado, el atentar contra el honor de un sujeto determinado, y conseguir realizar la afrenta, en este caso verbal, y sometida a los límites del convicium esto es, en grupo, en público, y por supuesto, adversus bonos mores. Ahora bien, no se enumeran los sujetos que pueden ser defendidos con la cláusula edictal -como sucede por ejemplo en el edictum de adtemptata pudicitia- sino que se deducen en cada caso concreto. La única referencia que nos brinda Ulpiano en cuanto a la objetivación de un posible sujeto pasivo, se encuentra en D. 47, 10, 15, 13, pero como bien dice Marrone ${ }^{41}$, no parece que el texto se refiera al edicto de convicio, sino que "tenuto presente il contenuto di esso, è probabile che si riferisse all'editto «ne quid infamandi causa fiat»": Si quis astrologus, vel qui aliquam illicitam divinationem pollicetur, consultus aliquem furem dixisset, qui non erat, iniuriarum cum eo agi non potest, sed Constitutiones eos tenent.

Ya en referencia al elemento intencional, debemos señalar que el matiz relevante que identifica el ilícito del convicium como delito especial de injurias es el dolo, ese dolus malus que se exige para condenar una determinada conducta, lo que significa que la injuria debía inferirse de forma voluntaria, y con intención de causar un perjuicio moral ${ }^{42}$, lo que supone la presencia en la iniuria de un animus iniuriandi. La intencionalidad en el agresor que causa la ofensa, es decir, el animus iniuriandi ${ }^{43}$, se refleja en un fragmento de Ulpiano, D. 47, 10, 3 (Ulp. 56 ad ed.), en relación con la consideración de sujeto activo y pasivo del delito de iniuria:

${ }^{41}$ Ibid., p. 482.

${ }^{42}$ La mayor parte de la doctrina considera como presupuesto de la iniuria el dolo cualificado, la intención clara de cometer la injuria condenable, pudiendo destacar a FERRINI, Diritto Penale, cit. p. 235; RABER, Grundlagen, cit. p. 108 ss.; DEVILLA, NNDI, 8, 1962, s.v. Iniuria; MARRONE, "Considerazioni", cit. p. 485, cuando afirma: "Altri ancora erano i requisiti dell'offesa morale, affinchè questa fosse giuridicamente repressa: requisiti obiettivi ... e requisiti soggettivi (animus iniuriandi)"; KURYLOWICZ, "Paul. D. 47, 10, 26 und die Tatbestände der römischen Iniuria", Labeo 33, 1987, p. 302.

${ }^{43}$ Vid. al respecto, PLESCIA, "The development of iniuria", cit. p. 272, en donde declara "Dolus (evil intent, animus iniuriandi)", añadiendo en n. 6 que el dolo "need not be explicit, it may be presumed". 
I llud relatum peraeque est eos, qui iniuriam pati possunt, et facere posse.

§1.- Sane sunt quidam, qui facere non possunt, utputa furiosus et impubes, qui doli capax non est : namquehi pati iniuriam sol ent, non facere; quum enim iniuria ex affectu facientis consistat, consequens erit dicere, hos, sive pul sent, sive convicium dicant, iniuriam fecisse non videri ${ }^{44}$.

$\S 2$.-I taque pati quis iniuriam, etiamsi non sentiat, potest, facere nemo, nisi qui scit, se iniuriam facere, etiamsi nesciat, cui faciat.

§ 3.- Q uare si quis per iocum percutiat, aut dum certat, iniuriarum non tenetur.

$\S 4$.- Si quis hominem liberum caeciderit, dum putat servum suum, in ea causa est, ne iniuriarum teneatur.

Resulta meridianamente claro que la falta de animus iniuriandi en quien carece de capacidad, le exime de responsabilidad alguna, lo que sin duda apoya los argumentos de la necesaria presencia del ánimo de ofender a alguien, la intención dolosa de injuriar y causar un daño en otra persona. La necesidad del elemento intencional se refleja así mismo en Paulo, D. 47, 10, 4 (50 ad. ed. $)^{45}$ : Si, quum servo meo pugnum ducere vellem, in proximo te stantem invitus percusserim, iniuriaum non teneor. A tenor de las palabras de Paulo podemos colegir que el dolus malus, resulta un elemento imprescindible para la configuración del delito de injurias, pero, como dice $\mathrm{Kaser}^{46}$, el dolo no es un requisito que resulte necesario probar, ya que está implícito en el delito legalmente tipificado, y en consecuencia, probado el hecho, se tendrá por probado el dolo, lo que reafirma que la explícita mención del mismo no haya sido requerida. Además del dolus malus, debe existir un hecho injurioso en clara correspondencia con el elemento subjetivo, pues al animus debe continuarle un elemento objetivo que puede incluso determinar que un supuesto sea considerado como iniuria y no como otro delito, como podría ser el damnum iniuria ${ }^{47}$.

\footnotetext{
${ }^{44}$ IEn el mismo sentido, PS 5. 4. 2; vid. sobre la imputabilidad del infans y furiosus, FERRINI, "Esposizione storica e dottrinale del diritto penale romano", en Enciclopedia del diritto penale, Milán, 1905, p. 39, en donde habla de la ausencia en las fuentes de un término equivalente al de imputación, existente en la teoría moderna del delito, ya que imputare tiene un significado diferente. Pero a pesar de no estar elaborado dicho concepto, sí se observan casos de no imputabilidad del infans y del furiosus, como en Ulpiano D. 21, 1, 23, 2 (1 ad ed. aed. cur.); Paulo D. 50, 17, 108 (4 ad ed.) y D. 48, 10, 22, pr (lib. sing. ad sen. Lib.); HAGEMANN, Iniuria, cit. p. 102: "Die Kernaussage des ersten Paragraphen, es gebe Menschen, die keine iniuria verüben könnten, weil sie nicht doli capax seien und iniuria ex affectu facientis consistat, wird in $\S 2-4$ erweitert: Nicht nur, wer generell nicht doli capax ist, begeht keine iniuria, sondern auch, wer im konkreten Fall nicht de entsprechenden dolus hat".

${ }^{45}$ Cfr. RABER, Grundlagen, cit. p. 110, cuando relaciona el pasaje de D. 47, 10, 3, con este de Paulo, para plantear a continuación una serie de interrogantes: "Doch geht es in diesem Zusammenhang weniger um eine Klärung dieses Problems als um die Feststellung, welche Tragweite der Satz cum enim iniuria ex affectu facientis consistat im klassischen Recht hatte. Galt er uneingeschränkt in dieser allgemeinen Formulierung, wöfur auch der Text von Paulus D. 47, 10, 4 spräche? Oder war sein Anwendungsbereich in sachlicher Hinsicht auf bestimmte Injurientatbestände, in persönlicher auf einzelne Personengruppen beschränkt? Worauf hatte sich der affectus des Täters zu beziehen? Welchen Inhalt hatte das Wort im Recht der iniuria? Wird es überhaupt in allen Injurienstellen in der gleichen Bedeutung verwendet?".

${ }^{46}$ KASER, "Typisiert dolus im altrömischen recht", en BIDR 1962, p. 79 ss.

${ }^{47}$ BIRKS, "Ulpian 18 ad edictum: introducing damnum iniuria", en Collatio iuris romani. Études dédiées à Hans Ankum, Amsterdam, 1995, p. 94 ss.
} 
Refiriéndonos ya en concreto al edicto de convicio, debemos destacar la presencia del elemento subjetivo o intencional. Para poder diferenciar conceptualmente nuestro ilícito debemos analizar la intención ${ }^{48}$ con la que se causa una lesión a otro sujeto, teniendo claro además que en este caso no se trata de un daño corporal, sino de una iniuria extra corpus, injuria verbal, que inflinge un resultado lesivo en otra persona pero no de carácter físico, sino referido a su honor, por cuanto lo que se busca es el menoscabo de su personalidad, el escarnio en presencia de otros a través del insulto realizado públicamente. Lo importante y esencial

${ }^{48}$ Cfr. la definición de Servio sobre el dolo malo recogida en D. 4, 3. 1. 2, dentro del título denominado De dolo malo, dedicado específicamente a esta acepción, en donde habla del elemento intencional: Dolum malum Servius quidem ita definiit, machinationem quandam alterius decipiendi causa, quum aliud simulatur, et aliud agitur; vid. en relación con esto, Ulpiano, en D. 2, 14, 7, 9, en donde reproduce la definición de Pedio sobre el dolus malus, en parte coincidente con la citada de Servio: Dolo malo ait Praetor pactum se non servaturum. Dolus malus fit calliditate et fallacia, et ut ait Pedius, dolo malo pactum fit, quoties circumscribendi alterius causa aliud agitur, et aliud agi simulatur ; sobre la autenticidad del pasaje de Servio dice CARCATERRA, Dolus bonus/Dolus malus. Esegesi di D. 4. 3. 1. 2-3, Nápoles 1970, p. 85: "Il passo di Pedio conferma l'autenticità della definitio di Servio"; añade en p. 88 n. 13 su desconcierto sobre la forma en que Ulpiano decide hablar sobre el dolo malo, eligiendo a Pedio en detrimento de Labeón, cuya acepción conocía; interesante la lectura del trabajo de GIACCHI, "Per una biografía di Sesto Pedio", en SDHI 62, 1996, p. 117, en donde analiza un fragmento del libro octavo ad edictum de Pedio recogido por Ulpiano en D. 4.3.1.4 (Ulp. 11 ad ed.) referente a la rúbrica edictal de dolo malo, cuyo tenor literal es el siguiente: Ait praetor: 'si de his rebus alia actio non erit'. Merito praetor ita demum hanc actionem pollicetur, si alia non sit quoniam famosa actio non temere debuit a pretore decerni, si sit civilis vel honoraria, qua possit experiri: usque adeo, ut et Pedius libro octavo scribit, etiamsi interdictum sit quo quia experiri, vel exceptio qua se tueri possit, cessare hoc edictum. Idem et Pomponius libro vicensimo octavo, et adicit: et si stipulatione tutus sit quis, eum actionem da dolo habere non posse, ut puta si de dolo stipulatum sit. Idem Pomponius ait[...].La autora nos dice que en este texto se comenta la rúbrica edictal de dolo malo, a lo que añade: "Nella rubrica de dolo malo si determinavano, tra l'altro, i presupposti necessari per la concessione dell'actio de dolo, strumento di carattere sussidiario che tutelava il soggetto vittima di un raggiro. Dopo aver riportato i verba edicti, Ulpiano ricorda le definizione del termine dolus date dalla giurisprudenza più antica: Servio e, in particolare, Labeone. Prosegue, poi, il commento concentrandosi sulle parole dell'editto si alia actio non erit. Il problema specifico che si impone all'attenzione del giurista è individuare l'ambito di applicazione dell'actio doli. Ulpiano, nel proporsi questo obiettivo, intende definire il carattere sussidiario di questo strumento di tutela e, in questo contesto, il giurista severiano ricorre al pensiero di Pedio per strutturare un punto importante della propria argomentazione. Come il testo ci ricorda, l'actio doli ha una applicabilità limitata dal fatto che si tratta di un'actio famosa. Parte della storiografia romanistica, rispetto a questo carattere dell'actio doli, ha invece sottolineato maggiormente l'influenza che ebbero le circostanze nelle quali sorse l'istituto. Quest'ultimo, infatti, avrebbe tratto origine proprio dall'intento di dare tutela a quelle situazioni che ne fossero rimaste prive sulla base dei rimedi esistenti"; anteriormente, en la misma dirección, ALBANESE, "La sussidiarietà dell'actio de dolo", en AUPA 28, 1961, p. 304 ss. en donde afirma que el hecho de que la actio doli sea una acción infamante no es la causa de la subsidiariedad, y que en D. 4. 3. 1 se trata de "un'osservazione stilizzata di Ulpiano, per sottolineare l'esigenza di cautela che il pretore impone a se stesso"; contra, GUARINO, "La sussidiarietà dell'actio de dolo", en Labeo 8, 1962, p. 272, en donde sostiene que este argumento planteado para reafirmar la genuinidad del pasaje, que lleva a "sminuire la portata giustificativa della sussidiarietà", resulta poco convincente. 
en este ilícito es la presencia o no del dolo ${ }^{49}$ en el autor del mismo, ya que la voluntariedad en el convicium, la intención clara de ofender a otra u otras personas es la que indica la imputabilidad o no del sujeto que profiera la injuria verbal. Además, el elemento subjetivo se ve acompañado en el caso concreto del convicium del requisito de la pluralidad de autores ${ }^{50}$ en la comisión del delito, por cuanto la palabra convicium nos refiere la necesidad de varios sujetos que, con capacidad de actuar, y con la intención de injuriar a alguien, se dirigen en público, en grupo, en presencia de otros y con vociferación contra el sujeto pasivo, lo que sin duda causará un detrimento mayor en el honor del destinatario que si el ilícito se cometiese en otras circunstancias. Con todo, la necesaria conjunción de un plural animus iniuriandi en lo que se refiere a los autores del ilícito debe ir acompañada de la imprescindible existencia de un sujeto o sujetos pasivos a quienes vaya inferida la ofensa. Resulta evidente que si se infiriese una injuria verbal sin concretar a quién se dirige el insulto del convicium, no produciría efecto alguno, por lo que tampoco se concede ninguna acción al efecto.

\footnotetext{
${ }^{49}$ Sabiendo que no resulta tarea fácil el determinar la presencia o no del dolo, dado su carácter intencional; de acuerdo con esto, vid. BLANCH NOUGUÉS, J.M., "Nota a propósito de la actio de dolo y su carácter infamante”, en Estudios Homenaje a Juan Iglesias 3, Madrid 1988, p. 1153: “...la dificultad añadida, que presentaba la actio de dolo, de la demostración de un elemento intencional como es el dolo, frente a la sencillez de tramitación de la correlativa actio in factum"; recientemente, CORBINO, "Eccezione di dolo generale: suoi precedenti", en L'eccezione di dolo generale. Diritto romano e tradizione romanística, Padua, 2006, p. 44-45, cuando al hablar de la presencia del dolo en el procedimiento formulario, dice: "Ed è per questo, ritengo, che Cicerone attribuisce ad Aquilio Gallo come merito non quello di avere preso in considerazione il dolo ... ma quello di avere prediposto 'formule'... in grado di contrastarlo con efficacia: Canio, dice il nostro, si era trovato nei guai perché nondum enim C. Aquilius, collega et familiaris meus, protulerat de dolo malo formulas (off. 3. 14. 60). Perché non vi erano insomma ancora quegli strumenti che avrebbero permesso allo stesso Cicerone di ricordare il proprio amico come colui che era stato, con le sue formule de dolo appunto, everriculum malitiarum omnium (de nat. deor.3. 30. 74). È solo la conceptio della formula che permette alla circostanza in difesa fatta valere (il dolo) di assumere un rilievo 'decisivo' (vincola il giudice a pronunziarsi conseguentemente)".

${ }^{50}$ Vid. al respecto la opinión de HENDRICKSON, "Convicium", cit. p. 116 ss. en donde afirma que la creencia de que convicium implica la presencia de una multitud o muchedumbre es claramente errónea, declarando en p. 119: "It is spun out of an assumed etymology, which Ulpian does not in fact entirely indorse, but merely advances in explanation of one aspect of his twofold conception of convicium. But while not accepting it unreservedly, he yet rests one leg of his structure upon it. This is the starting point of the modern doctrine, which, failing to note the alternatives, has accepted the idea of a plurality of voices or persons as the unqualified teaching of the jurists. Convicium has necessarily no more to do with a plurality of utterance than has clamor, or the ancient pipulum and vagulatio, both of which are defined by convicium. To be sure a mob might shout insults at an individual, and these were convicia, not however, because they were shouted by a crowd or in chorus -quasi convocium, but because they were vehement expressions of hostile feeling- a concitatione, and meant to overwhelm (convincere); contra, WITTMANN, Die Körperverletzung an Freien im klassischen römischen Recht, Munich, 1972, p. 29, cuando afirma: "convicium ist jedenfalls ursprünglich ein Schimpfkonzert, das von mehreren gegen jemanden veranstaltet wird", dejando claro el espíritu colectivo de los que realizan una afrenta verbal contra otro; posteriormente, en "Die Entwicklungslinien", cit. p. 308, en donde niega el ilícito realizado de forma individual, afirmando que el edicto condena única y exclusivamente la actitud de una pluralidad de personas.
} 
El animus iniuriandi lleva implícito el deseo o la intención de causar un resultado lesivo en otra persona -por lo tanto determinada a priori- que es a la que van dirigidos los ataques verbales. Sin esa determinación previa del sujeto que va a ser el destinatario final del convicium no se puede colegir que estemos ante la presencia de un supuesto ilícito, y por lo tanto, susceptible de ser perseguido.

Para poder condenar una determinada conducta, debe existir además una relación directa entre las palabras proferidas y la recepción de las mismas por parte del injuriado o agraviado con las mismas, y como hemos dicho anteriormente, debe tratarse de un sujeto concreto.

El elemento intencional es el requisito esencial para condenar la injuria verbal proferida, ante la cual el pretor concederá una acción, la actio iniuriarum, recordando la necesidad, en el caso concreto del convicium, que se realice en grupo y con vociferación ${ }^{51}$, ya que si no el animus iniuriandi se entendería referido al infamandi causa dictum, y no a nuestro edicto.

La naturaleza subjetiva de la protección concedida en el edictum de convicio demuestra la importancia del nexo causal entre la intención ínsita en el animus iniuriandi y el resultado lesivo que recibe el sujeto pasivo de una injuria verbal. Se castiga la intención con la que se profiere el convicium, que debe realmente producir un menoscabo en el honor de alguien, que constituye el resultado querido por los autores del ilícito. Sin olvidar, en cualquier caso, la tarea harto difícil de identificar a los que intervienen de forma activa en esta injuria verbal colectiva a la hora de atribuirles el correspondiente delito. Debe existir una relación de causa a efecto entre los autores de la injuria verbal y el resultado producido ${ }^{52}$, por lo que el elemento subjetivo del edictum de convicio nos informa de la necesaria responsabilidad subjetiva para tipificar un acto como susceptible de ser perseguido y condenado cuando se realiza un convicium.

Para terminar, quiero incidir de nuevo en la singularidad de este edicto, conocido por la reconstrucción de Lene ${ }^{53}$, y que reside precisamente en su propio nombre, convicium, que indica la presencia necesaria del elemento colectivo a la hora de cometer el delito perseguido. Con todo, nos encontramos ante un edicto poco conocido y menos estudiado que otros de contenido más general, de ahí que haya despertado mi interés en analizar jurídicamente el motivo de su existencia y el contenido de la protección edictal contenida en el mismo.

\footnotetext{
${ }^{51} \mathrm{~S}$ Como se refleja en las palabras de Ulpiano recogidas en D. 47, 10, 7, 5: Si mihi plures iniurias feceris, puta, turba et coetu facto domum alicuius introëas, et hoc facto efficiatur, ut simul et convicium patiar...

${ }^{52}$ Cfr. RODRÍGUEZ ENNES, "Reflexiones en torno a diversos delitos de Derecho honorario", en El derecho penal: de Roma al derecho actual, VV. AA., Madrid, 2005, p. 530, cuando al hablar de la acción edilicia de feris, afirma: "Existe, pues, un nexo de causalidad, una relación de causa a efecto entre el autor material del factum y el resultado dañoso: responde única y exclusivamente el detentador del animal peligroso causante del daño. Se trata, por tanto, de una responsabilidad subjetiva en la que incurrió el autor del daño, que con su conducta descuidada desencadenó el evento damnificador".

${ }^{53}$ En EP3, Leipzig, 1927, reimp. 1985.
} 


\section{O EDITO DE CONVÍCIO}

Resumo: Trata-se aqui de estudo sobre o edito de convício, um delito de injúria verbal realizada de forma coletiva, com a intenção clara de ofender a vítima, independentemente da sua presença no momento da ofensa. Ocorria quando se ofendiam os bons costumes, especialmente como mores huius civitatis. Tratava-se de um edito especial, ao qual se tem dado pouca atenção de modo individualizado, sendo nosso propósito o de identificar os elementos objetivos e subjetivos, para que seja reconhecido como figura singular.

Palavras-chave: I niuria. E dictum. Convicio. B onos mores. D olus. 